\title{
MEJORAMIENTO DE MAÍCES CRIOLLOS DE HONDURAS MEDIANTE LA APLICACIÓN DE METODOLOGÍAS DE FITOMEJORAMIENTO PARTICIPATIVO11
}

\author{
Juan Carlos Rosas-Sotomayor ${ }^{2}$, Omar Gallardo-Guzmán ${ }^{3}$, José Jiménez-Torres ${ }^{3}$
}

\begin{abstract}
RESUMEN
Mejoramiento de maíces criollos de Honduras mediante la aplicación de metodologías de fitomejoramiento participativo. En Honduras, la baja productividad del cultivo de maíz se debe en gran parte a las condiciones marginales, bajo uso de insumos y maquinaria utilizados para su cultivo. Por otro lado, las variedades criollas utilizadas por los pequeños agricultores de Honduras se caracterizan por presentar algunas características agronómicas indeseables, incluyendo plantas demasiado altas susceptibles al acame y de bajo potencial de rendimiento, pero poseen excelentes cualidades culinarias. Las variedades criollas de maíz se están mejorando mediante la utilización de métodos de fitomejoramiento participativo (FP) para generar variedades mejoradas que combinen la adaptación específica con los caracteres deseados por los pequeños productores y sus familias. Los enfoques de FP han permitido generar variedades de frijol y maíz que superan a las variedades criollas predominantes en comunidades de Yorito y el Lago Yojoa, en Honduras. En este documento se describe las actividades y experiencias en el proceso de aplicación de metodologías de FP para el mejoramiento de variedades criollas de maíz con grupos de agricultores organizados en Comités de Investigación Agrícola Local (CIAL).
\end{abstract}

Palabras claves: Fitomejoramiento participativo, maíz, Zea mays, Comités de Investigación Agrícola Local (CIAL).

\begin{abstract}
Improvement of Honduran maize landraces by applying participatory plant breeding methodologies. In Honduras, the low productivity of maize is due to marginal conditions, low input use and lack of machinery suitable for this crop. On the other hand, the landrace varieties used by small farmers in Honduras are characterized by some undesirable traits, including extremely tall plants susceptible to lodging and with low yield potential, but with excellent culinary characteristics. These landrace varieties of maize are being improved using participatory plant breeding (PPB) methods to generate improved varieties that combine specific adaptation with desirable traits for small farmers and their families. These PPB approaches have allow the generation of bean and maize varieties which are superior to the predominant landraces in communities of the regions of Yorito and the Yojoa Lake of Honduras. This document describes the activities and experiences during the process of application of PPB methodologies for the improvement of maize landraces with farmers organized in Local Agricultural Research Committees (CIAL).
\end{abstract}

Key words: Participatory plant breeding, maize, Zea mays, Local Agricultural Research Committees (CIAL).

\section{INTRODUCCIÓN}

El maíz (Zea mays) es el grano básico más importante en Mesoamérica, siendo desde tiempos precolombinos la base de la alimentación de los pobladores de esta región geográfica. Su evolución como cultivo se llevó a cabo por los agricultores, quienes seleccionaron y generaron innumerables variedades

1 Recibido: 16 de mayo, 2006. Aceptado: 24 de agosto, 2006.

2 Escuela Agrícola Panamericana, Zamorano. Apartado postal 93, Tegucigalpa, Honduras. Correo electrónico: jcrosas@zamorano.edu

3 Fundación para la Investigación Participativa con Agricultores de Honduras (FIPAH). Edicio Plaza del Caribe, Apt. 207, La Ceiba, Honduras. 
criollas que llegaron a formar parte de la dieta y costumbres alimenticias de diferentes pueblos.

En Honduras, el maíz continúa siendo la base de la alimentación y es consumido por todas las clases socioeconómicas del país. En 1999-2000, el consumo aparente per cápita de maíz en Honduras fue de 31,4 $\mathrm{kg}$. Alrededor del $70 \%$ del maíz consumido es producido por pequeños productores en parcelas menores a 3,5 ha. En el año 2000 se produjeron en Honduras un total de 543.078 t de maíz blanco en 378.558 ha (Cotty et al. 2001). El rendimiento promedio nacional en el año 2000 fue de 1,4 t/ha, el cual estuvo relativamente por debajo del promedio de 1,8 t/ha en los trópicos, pero sobretodo con relación al promedio mundial de 4,2 t/ha (Paliwal et al. 2000).

La baja productividad del maíz en Honduras es el resultado de su cultivo en suelos marginales, incluyendo terrenos de laderas; de la baja capacidad económica de los agricultores, que no les permite la aplicación de insumos básicos y la mecanización del cultivo; y del uso de variedades criollas, que pese a estar adaptadas a condiciones ambientales desfavorables, tienen un bajo potencial productivo y son afectadas por enfermedades que reducen su calidad y rendimiento.

\section{ANTECEDENTES DEL FITOMEJORAMIENTO PARTICIPATIVO EN HONDURAS}

Durante el período de 1993-96, la Escuela Agrícola Panamericana Zamorano en colaboración con la Universidad de Cornell, condujo trabajos de investigación sobre el impacto potencial de metodologías participativas en el mejoramiento de variedades criollas de maíz en Honduras (Gómez y Smith 1996; Gómez et al. 1995). Aunque las actividades de este proyecto no fueron continuadas, los resultados obtenidos durante su vigencia fueron alentadores, incluyendo la aplicación de principios genéticos por los agricultores para mejorar los métodos de selección tradicionalmente empleados en el mantenimiento de sus variedades criollas; así como el mejoramiento de características agronómicas de las poblaciones criollas utilizadas.

Para continuar con los avances en el desarrollo de una metodología de fitomejoramiento participativo
(FP) de maíz más efectiva, desde el año 2000 se viene conduciendo un proyecto de FP en los que se han incorporado algunas modificaciones relacionadas con la variabilidad genética del cultivo y los métodos de selección anteriormente empleados. Bajo este proyecto, se han conducido actividades de FP para ampliar la base genética de las poblaciones criollas introduciendo genes de caracteres de interés para los agricultores, incluyendo aquellos que facilitan el manejo del cultivo, como la reducción de la altura de planta y de la primera mazorca, resistencia al acame, mayor precocidad a la madurez, y mejor potencial de rendimiento, este último mediante el incremento en el número de hileras por mazorcas, mazorcas de mayor tamaño y/o mayor número de mazorcas por planta. Por otro lado, se ha enfatizado en la selección por resistencia a enfermedades como pudrición de la mazorca y plagas de almacenamiento.

Durante el proceso de selección se ha venido enfatizando en el mantenimiento de los caracteres deseables presentes en las variedades criollas, incluyendo la adaptación a condiciones adversas, buena cobertura de la mazorca (relacionada con una menor incidencia de la pudrición de la mazorca), el tamaño y color del grano, y la calidad culinaria para la elaboración de tortillas y otros alimentos, entre otras. Muchas de las características deseables de las variedades criollas, son el resultado del mejoramiento realizado por los agricultores desde la antigüedad; estos atributos son los que determinan la enorme preferencia de estas variedades por la gran mayoría de los productores de la región.

\section{ZONA DE INFLUENCIA DEL PROYECTO}

Las acciones durante la primera fase del proyecto FP en Honduras se concentraron en comunidades de Yorito, departamento de Yoro, y comunidades ubicadas alrededor del Lago Yojoa, en los departamentos de Santa Bárbara y Comayagua. Estas regiones se caracterizan por condiciones de extrema pobreza, y está conformada por grupos de pobladores mestizos e indígenas cuya principal actividad es la agricultura de subsistencia, basada primordialmente en la producción de granos básicos para consumo familiar y comercialización local. En estas regiones, el consumo per cápita de maíz y frijol normalmente duplica al promedio nacional, siendo estos granos básicos las principales fuentes de calorías y proteínas. 
Las unidades de producción de los pobladores de estas regiones son fincas en terrenos de laderas, caracterizadas por suelos marginales de baja productividad y susceptibles a la erosión. En ellas se cultivan principalmente maíz y frijol en sistemas adaptados a los patrones de distribución de lluvias de cada región, que con frecuencia limitan la diversificación agrícola y productividad de estos cultivos, y cuyos rendimientos generalmente son inferiores a los promedios nacionales. Adicionalmente, la actividad agrícola en estas regiones es limitada por la baja capacidad económica de los productores y la falta de acceso a los mercados para la adquisición de insumos y la comercialización de sus productos.

La gran mayoría de estos agricultores utiliza maíces criollos desarrollados bajo las condiciones de la región, que aunque se caracterizan por su adaptación a los sistemas de producción tradicionales, tienen bajo potencial de rendimiento y una eficiencia fisiológica limitada para responder a un manejo adecuado del cultivo. Adicionalmente, la mayoría de estos maíces presentan alta susceptibilidad a las enfermedades y plagas predominantes.

\section{EL FITOMEJORAMIENTO CONVENCIONAL Y LOS PEQUEÑOS AGRICULTORES}

El mejoramiento genético es una de las alternativas más factibles para elevar la producción de los cultivos tradicionales como el maíz. Sin embargo, este debe estar orientado hacia las condiciones de los pequeños agricultores para lograr aumentar su calidad de vida y promover la sostenibilidad de la agricultura en sus zonas de producción. Aunque existen variedades híbridas y cultivares mejorados de polinización abierta con alto potencial de rendimiento y resistencia a enfermedades; generalmente, estas variedades no se adaptan a las condiciones de bajo uso de insumos y al manejo del cultivo con prácticas tradicionales de los agricultores. En la mayoría de los casos, bajo estas condiciones menos favorables, los rendimientos de las variedades mejoradas son inferiores a los de los cultivares criollos o a las variedades mejoradas de uso tradicional (variedades "acriolladas").

\section{EL FITOMEJORAMIENTO PARTICI- PATIVO COMO ALTERNATIVA}

Para que sea eficaz en términos de adaptabilidad y adopción, el mejoramiento debe efectuarse en fincas de agricultores considerando sus criterios y conocimientos locales, en adición a los aportados por el fitomejorador. Este procedimiento es conocido como fitomejoramiento participativo (FP) (Eyzaguirre e Iwanaga 1996; Weltzien et al. 2003). En la mayoría de los casos, para que el FP sea efectivo, es necesario ampliar la base genética para facilitar la introgresión de genes de alta producción y características deseables en las variedades criollas. De este modo, se podría desarrollar variedades criollas con mejor producción y resistencia a enfermedades, manteniendo su buena adaptación a las condiciones agroecológicas predominantes, así como la calidad de grano adecuada a sus necesidades. Adicionalmente, este procedimiento participativo permitiría la conservación in situ de germoplasma de maíz constituido por variedades criollas y acriolladas, manteniendo los genes que controlan la expresión de las características deseables sin afectar de forma radical la evolución natural como sucede con la mayoría de los sistemas de conservación ex situ.

El objetivo de las actividades de FP en maíz descritas en este documento, consiste en contribuir con el desarrollo de la capacidad de los agricultores para la conservación y mejoramiento genético de maíces criollos in situ, mediante la aplicación de metodologías para el fitomejoramiento participativo y la generación de variedades mejoradas más adecuadas a sus sistemas de producción y entornos socioeconómicos. Adicionalmente, se pretende incrementar los conocimientos, destrezas y habilidades de los productores y el fortalecimiento del liderazgo individual y el de sus organizaciones en sus comunidades.

\section{MATERIALES Y MÉTODOS}

\section{Actividades de FP de maíz en Honduras}

Las actividades de FP en maíz incluidas en este documento, fueron coordinadas por el Programa de Investigaciones en Frijol (PIF) de la Escuela Agrícola 
Panamericana Zamorano, y forman parte de la primera fase de un proyecto de FP en Honduras durante el período 2000-2005, vinculado al Programa Colaborativo para el Fitomejoramiento Participativo en la Región de Mesoamérica, y auspiciado por el Fondo de Desarrollo Noruego y la organización ACSUR de España. Durante esta fase, también se contó con el apoyo del Programa para la Investigación Participativa y Análisis de Género de los Centros Internacionales (PRGA/CGIAR) y el Bean/Cowpea CRSP-USAID, para conducir actividades de FP en el cultivo de frijol en Honduras. La aplicación de la metodología de FP en las comunidades, incluyendo las capacitaciones y talleres, fueron manejados en colaboración con técnicos y facilitadores de la Fundación para la Investigación Participativa con Agricultores de Honduras (FIPAH) y el Programa de Reconstrucción Rural (PRR), y con la participación de agricultores de los Comités de Investigación Agrícola Local (CIAL) asistidos por FIPAH y PRR en Yorito y el Lago Yojoa (Humphries et al. 2002), como se observa en la Figura 1.

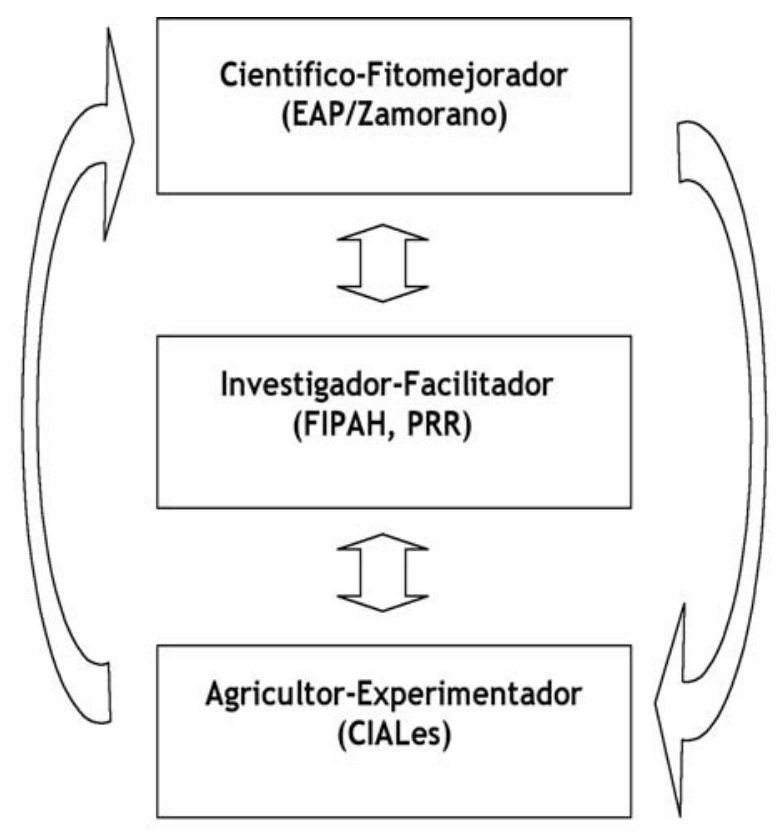

Figura 1. Diagrama de las interacciones y funciones entre el científico (fitomejorador), el técnico-investigador (facilitador) y el agricultor (experimentador) en las actividades de fitomejoramiento participativo en Honduras.
El programa PIF cuenta con un equipo técnicocientífico con amplia experiencia en fitomejoramiento e investigación participativa (IP) con pequeños agricultores (Rosas 2001a, Rosas 2001b; Rosas et al. 2003), manejo agronómico de cultivos de granos básicos, producción de semilla y capacitación de productores. Desde hace más de 15 años, el PIF conduce proyectos de investigación en colaboración con organizaciones y programas de investigación de la región Mesoamericana y El Caribe, y forma parte del Programa Colaborativo de Fitomejoramiento Participativo en Mesoamérica y del Programa Bean/Cowpea CRSP que conducen actividades de IP y FP en la región de Centro América y el Caribe.

El principal colaborador de este proyecto ha sido FIPAH, organización privada de desarrollo cuyas actividades en Honduras son coordinadas por una especialista en sociología de la Universidad de Guelph, Canadá y que cuenta con un equipo de técnicos expertos en IP. FIPAH es el pionero en el establecimiento de los Comités de Investigación Agrícola Local (metodología CIAL) en Honduras (Humphries et al. 2002); y asiste directamente a más de 35 CIAL en Yorito, Yoro.

El PRR es el principal colaborador en la región del Lago Yojoa donde se conducen actividades de FP desde hace más de cinco años, y proveen asistencia a 14 CIAL ubicados en comunidades de esta región (organizados como ASOCIOLAYO). Los CIAL en Honduras (más de 90 distribuidos en cinco regiones del país) están agrupados en una asociación nacional denominada ASOHCIAL, a través de la cual se diseminan los resultados de las actividades de IP, las tecnologías y materiales seleccionados por los agricultores. El PIF colabora con FIPAH y los CIAL asistidos por este proyecto, desde su inicio en 1993; adicionalmente, el PIF colabora con los CIAL asistidos por El Zamorano en la cuenca del Río Yeguare (asociados como ASOCIOGUARE), en los departamentos de El Paraíso y Francisco Morazán (Garrido 2004).

Personal técnico de FIPAH y el PRR colaboran con la supervisión de las actividades de FP de maíz en Yorito y el Lago Yojoa, respectivamente, y participan en la capacitación a los agricultores involucrados, y facilitan la diseminación del germoplasma criollo y las 
poblaciones mejoradas de maíz, así como los resultados de IP y FP a otras comunidades a través de las asociaciones regionales de CIAL.

Los CIAL están constituidos por agricultores organizados para promover el mejoramiento de la agricultura local a través de la participación activa de sus miembros en procesos de investigación, validación y transferencia de tecnologías (Ashby et al. 2000; Humphries et al. 2002). Cada comité define las áreas de interés para las investigaciones que conducen, con la asistencia técnica de organizaciones de desarrollo como FIPAH y PRR, que los capacitan en aspectos organizativos y técnicos. Los objetivos que se buscan a través de la metodología CIAL son el desarrollo sostenible de la capacidad local para realizar investigación, adaptar la tecnología local e integrar los conocimientos técnicos nativos y modernos.

\section{Metodologías para el fitomejoramiento participativo}

El paso inicial para la ejecución del proyecto fue la conducción de diagnósticos para caracterizar a las comunidades participantes. Estos diagnósticos incluyeron aspectos socioeconómicos como la composición del núcleo familiar, nivel de escolaridad, participación en la producción agrícola o en otro sector laboral, género, edad y otros; y sobre sus sistemas de producción de maíz, incluyendo aspectos de tenencia de la tierra, uso de insumos y destino de la producción.

La generación de las poblaciones mediante el entrecruzamiento por polinización controlada de plantas seleccionadas por los agricultores bajo un esquema participativo de mejoramiento y selección, se llevaron a cabo en Centros de Selección Participativa (CSP) establecidos en lotes accesibles a las comunidades involucradas.

La aplicación de las metodologías participativas para el mejoramiento de maíces criollos se ejecutó bajo dos alternativas: una metodología en la que el cruzamiento original entre la variedad criolla y las variedades mejoradas (criolla x mejorada), en la cual los ciclos de selección se condujeron en El Zamorano, y las evaluaciones de las poblaciones mejoradas de cada ciclo fueron realizadas directamente por los agricultores en los CSP ubicados en las comunidades participantes (FP-1).Una metodología de mejoramiento a partir de la variedad criolla sin utilizar hibridación, sino aplicando métodos de selección intrapoblacional, en la que la selección se efectuó por los agricultores en los CSP (FP-2), utilizando el método de surco por mazorca seguido de recombinación intrapoblacional.

Las actividades de mejoramiento y selección en los CSP y las evaluaciones de poblaciones mejoradas en fincas de agricultores se realizaron con la participación de agricultores de los CIAL de las comunidades involucradas, asistidos por FIPAH y el PRR.

Los criterios utilizados para identificar las variedades criollas y mejoradas involucradas en las hibridaciones, fueron definidos con base a los caracteres que los agricultores deseaban mejorar en estas variedades criollas; los cuales incluyeron, básicamente, la reducción de altura de la planta y a la primera mazorca, aumento de vigor y resistencia al acame, mayor precocidad, buena cobertura de la mazorca y mayor productividad. Se identificaron a "Capulín" y "Tuza Morada" como las variedades criollas más utilizadas en ese entonces en las regiones de Yorito y Lago Yojoa, respectivamente, como las candidatas a la primera fase de FP en estas regiones.

Las variedades mejoradas utilizadas en las hibridaciones para mejorar estas variedades criollas, fueron "HB104" y "Guayape", dos variedades liberadas en Honduras hace más de 15 años, y con una amplia diseminación en zonas maiceras de este país. Estas dos variedades mejoradas de Honduras fueron seleccionadas después de realizar evaluaciones de un grupo de accesiones mejoradas proveniente del CIMMYT, donde estas dos variedades demostraron tener mejores cualidades en cuanto a adaptación agronómica, resistencia a enfermedades y calidad de grano, y por ello se decidió usarlas como las poblaciones fuentes para mejorar las variedades criollas.

Para ilustrar las actividades FP en maíz en Honduras, en este documento sólo se detalla el proceso de cruzamiento y selección, y la validación de poblaciones mejoradas de maíz, llevado a cabo con los CIAL de la región de Yorito. En esta región, la población original, se conformó con base en un compuesto poblacional de la diversidad de maíz, en las comunidades participantes, representada por la variedad criolla predominante conocida como "Capulín". Esta población 
compuesta original (PCO) estuvo conformada por semilla cosechada de plantas superiores de la variedad criolla Capulín, identificadas en los lotes de producción de varios agricultores de las localidades de San Juancito, La Albardilla, Santa Cruz y La Esperanza, en el departamento de Yoro.

\section{Fitomejoramiento participativo de maíz mediante hibridación (FP-1)}

Para ampliar la base genética e introducir alelos deseables, bajo la metodología FP-1, en junio del 2000 se sembraron lotes aislados de la PCO en surcos alternos con la variedad mejorada denominada la población fuente (PF). Se utilizaron las variedades Guayape y HB104, ampliamente cultivadas por agricultores en Honduras por sus características agronómicas favorables, incluyendo altura de planta, precocidad, vigor vegetativo y reproductivo (características deseables de la mazorca y rendimiento de grano), y resistencia a plagas y enfermedades de almacén. La siembra para los cruzamientos de Capulín x Guayape (población CG) y Capulín x HB-104 (población CHB) se hizo en lotes aislados empleando una relación 4:1 (número de hileras de PCO:PF).

Se manejaron 2.000 plantas de la PCO y 400 de la $\mathrm{PF}$ aproximadamente, para cada cruzamiento. Las plantas de la PCO se despanojaron para asegurar que fueran polinizadas exclusivamente por polen de las plantas de la PF, y así facilitar la incorporación de genes deseados a la PCO. Las plantas de los cruzamientos PCO x PF de cada población fueron cosechadas individualmente. Un compuesto de semilla F1 de las plantas individuales de cada población, fue sembrado en enero del 2000 en lotes aislados en El Zamorano para su entrecruzamiento por polinización cruzada $(\sim 2,000$ plantas/población F1) utilizando riego. Estas poblaciones fueron denominadas CG-C0 y CHB-C0, es decir las poblaciones derivadas de cruzamientos de variedad criolla $\mathrm{x}$ mejorada antes de ingresar al proceso de selección.

La semilla de las poblaciones CG-C0 y CHB-C0 cosechada del lote de entrecruzamiento de las poblaciones CG y CHB, fue sembrada en junio del 2000 en lotes de evaluación en el CSP ubicado en la comunidad de Santa Cruz, Yorito en comparación con la variedad Capulín original. Simultáneamente, se sembró una parcela de estas poblaciones en Zamorano, para realizar el primer ciclo de selección con base en la identificación de plantas con caracteres deseables, durante las etapas vegetativas y reproductivas, por caracteres de mazorca y grano, a nivel de cosecha y poscosecha.

La comunidad de Santa Cruz, ubicada en el municipio de Yorito, departamento de Yoro, se encuentra en la región nor-central de Honduras, a una altura de 1.200-1.400 msnm. La topografía es mayormente de ladera, y los suelos son mayormente de bajo contenido de materia orgánica. La mayoría de agricultores usan variedades criollas y semilla de la cosecha anterior. La preparación del terreno es el tradicional, aunque la quema ha sido reducida en los últimos años. Se utilizaron muy pocos insumos, y mayormente incluyen la aplicación de un quintal/manzana $(65 \mathrm{~kg} / \mathrm{ha})$ de 18-46-0 u otra fórmula de fertilizante a la siembra y/o un quintal de urea al aporque. Las deshierba y la cosecha se realizan manualmente mediante mano de obra familiar.

Las comunidades vecinas que participaron en algunas actividades de este proceso de FP poseen características similares a las de Santa Cruz, siendo las mayores diferencias las relacionadas a la altitud en las que se encuentran estas comunidades, las que varían entre los 900 a $1.500 \mathrm{msnm}$.

Parte de la semilla PC1 colectada del lote de cruzamiento intrapoblacional fue sembrada en parcelas de evaluación, en fincas de varios agricultores de Yorito en junio del 2001. La semilla remanente de ambas poblaciones CG-C1 y CHB-C1, fue sembrada en Zamorano para llevar a cabo el segundo ciclo de selección (PC2). La semilla del segundo ciclo fue sembrada para la recombinación intrapoblacional en lotes aislados en el verano del 2002.

En junio del 2002, parte de esta semilla fue sembrada en varias localidades de Yorito para la evaluación de las poblaciones CG-C2 y CHB-C2, la PCO de Capulín, y los padres Guayape y HB-104, en fincas de agricultores.

En el verano del 2003, la semilla de las plantas seleccionadas de las PC2 fue sembrada para su recombinación poblacional y generación de la nueva población derivada del ciclo 3 de selección (PC3). En junio del 2003, las poblaciones CG-C3 y CHB-C3 
fueron sembradas para su evaluación por agricultores en varias localidades de Yorito; en estos ensayos se incluyeron la PCO y la variedad "Capulín Mejorado" (variedad mejorada a través de selección de Capulín sin hibridación) como testigos. Adicionalmente, en esa misma época se sembraron en El Zamorano, las poblaciones de los cruzamientos iniciales (CG-C0 y CHB$\mathrm{C} 0$ ), las provenientes de los tres ciclos de selección (CG-C1, CG-C2, CG-C3, CHB-C1, CHB-C2 y CHBC3), Capulín Mejorado (población mejorada a partir de la variedad Capulín sin hibridación), para realizar incrementos de semilla a fin de llevar a cabo un ensayo en el 2004 para estimar la ganancia por selección alcanzados por el proceso de FP durante los tres ciclos.

\section{Fitomejoramiento participativo de maíz por selec- ción de la variedad criolla (FP-2)}

En la aplicación de esta alternativa, se utilizó la población PCO de la variedad Capulín a partir de un compuesto masal de semilla de agricultores de varias localidades, quienes participaron en las actividades de FP, región de Yorito. Bajo esta alternativa FP2, en la PCO se aplicaron cuatro ciclos de selección intrapoblacional usando el método de selección de surco por mazorca (aproximadamente 400 mazorcas seleccionadas en cada ciclo), seguidos de lotes de recombinación de las familias seleccionadas (aproximadamente $20 \%$ ) después de cada ciclo de selección. Todo este proceso de FP2 se llevó a cabo en el CSP ubicado en Santa Marta y otras localidades cercanas.

Las poblaciones desarrolladas por los agricultores en los CSP (alternativa FP2) y las del fitomejorador (alternativa FP1), fueron comparadas a través de las evaluaciones en fincas de agricultores en el 2003-04, de forma que se pudiera estimar las diferencias en ganancia por selección de cada alternativa, y medir el impacto del FP. Para facilitar la comparación entre ambos procedimientos, en ambos casos el mejoramiento se comenzó a partir de la misma PCO de la variedad Capulín.

Las poblaciones fuentes fueron seleccionadas con base en diagnósticos participativos, que permitieron identificar la problemática de la producción de maíz en las comunidades objetivo; las características deseables de las variedades criollas a ser mantenidas en las nuevas variedades y las características que se deseaban mejorar incorporando alelos deseables de poblaciones fuentes escogidas por su superioridad en estos aspectos. Al final de cada ciclo de selección se establecieron ensayos en fincas de agricultores, para estimar los avances genéticos obtenidos con cada alternativa de mejoramiento, y dar acceso a los productores a las poblaciones mejoradas después de cada ciclo.

Debido a que en Honduras la participación de la mujer en la producción de maíz se concentra principalmente en las etapas de cosecha y poscosecha, se enfatizó en su participación en aspectos de selección relacionados al valor comercial del grano, calidad de consumo (culinaria) y almacenamiento, y en la selección de semilla. Sin embargo, en algunos CIAL las mujeres juegan un rol importante en las actividades de campo, incluyendo las evaluaciones de germoplasma.

\section{RESULTADOS Y DISCUSIÓN}

Dos variedades de maíz fueron desarrolladas mediante los dos enfoques de FP aplicados para mejorar la variedad criolla Capulín en la región de Yorito (Hocdé 2006). Estas variedades fueron liberadas con los nombres de "Santa Cruz" y "Capulín Mejorado" durante el 2005, después de dos años de validaciones a nivel de finca. La variedad Santa Marta es el resultado de la selección de las poblaciones CHB (Capulín x HB104) y CG (Capulín x Guayape) de los ciclos 1 , 2 y 3 de selección de medio-hermanos realizados en Zamorano, y evaluaciones en CSP y fincas de agricultores conducidas en Santa Cruz y otras comunidades de Yorito. Estas poblaciones derivadas de cruzamientos de la variedad criolla Capulín, y dos variedades mejoradas, fueron desarrolladas a través de la alternativa de mejoramiento participativo mediante hibridación (FP1), descrita en materiales y métodos.

Una de las características principales de la variedad de maíz blanco Santa Cruz es su excelente adaptación a condiciones de altura de 900 a 1.200 msnm (Gallardo et al. 2005a). Con respecto a la variedad Capulín original (altura 3,1 m), en la variedad Santa Cruz, se redujo la altura de planta a $2,6 \mathrm{~m}$ y de la mazorca a 1,3 m (Cuadro 1). Los rendimientos promedios de la variedad Santa Marta en pruebas realizadas en comunidades del departamento de Yoro fueron de 
Cuadro 1. Características de la planta, mazorca y grano, y rendimiento de grano $(\mathrm{kg} / \mathrm{ha})$ de las variedades Santa Cruz y Capulín Mejorado con relación a la variedad criolla Capulín utilizada como testigo. Yorito, Honduras, 2003-04.

\begin{tabular}{lccc}
\hline \multicolumn{1}{c}{ Característica* } & $\begin{array}{c}\text { Santa } \\
\text { Cruz }\end{array}$ & $\begin{array}{c}\text { Capulín } \\
\text { mejorado }\end{array}$ & $\begin{array}{c}\text { Capulín } \\
\text { criollo }\end{array}$ \\
\hline Altura planta (m) & 2,6 & 2,7 & 3,1 \\
Altura 1ra. mazorca (m) & 1,3 & 1,4 & 1,8 \\
Longitud mazorca (cm) & 20 & 20 & 18 \\
Diámetro mazorca (cm) & 6 & 6 & 6 \\
No. hileras & $14-16$ & 14 & 12 \\
Forma grano & Dentado & Dentado & Dentado \\
Consistencia grano & Semi- & Semi- & Semi- \\
& cristalino & cristalino & cristalino \\
Color grano & Blanco & Blanco & Blanco \\
Días a floración & 60 & 65 & 72 \\
Días a madurez fisiológica & 105 & 110 & 120 \\
Rendimiento (kg/ha) & 5.036 & 5.503 & 4.465 \\
\hline
\end{tabular}

* Los datos de planta, mazorca y grano fueron tomados en la localidad de Santa Cruz; los datos de días a floración, madurez fisiológica y rendimiento de grano, son los promedios de datos tomados en parcelas de validación en 12 localidades del Municipio de Yorito.

$5.036 \mathrm{~kg} / \mathrm{ha}$, comparado a los de Capulín original de $4.465 \mathrm{~kg} / \mathrm{ha}$. Asimismo, la variedad Santa Cruz conserva las cualidades del grano de forma dentada, consistencia semi-cristalina y de color blanco de la criolla Capulín.

La variedad Capulín Mejorado es el resultado de las selecciones medio-hermano (surco por mazorca) efectuadas durante tres ciclos en la población original de la variedad criolla Capulín, siguiendo la alternativa de mejoramiento participativo intrapoblacional (FP2), descrita en materiales y métodos. La principal característica de la variedad Capulín Mejorado es su adaptación a un rango amplio de altitud (1000 a $1800 \mathrm{msnm}$ ) (Gallardo et al. 2005b). Posee una altura de planta (2,7 $\mathrm{m})$ y altura de la mazorca $(1,4 \mathrm{~m})$ menor que la variedad original (Cuadro 1). En evaluaciones en el Departamento de Yoro, el rendimiento promedio de la variedad Capulín Mejorado fue de $5.503 \mathrm{~kg} / \mathrm{ha}$ y la del Capulín original de $4.465 \mathrm{~kg} / \mathrm{ha}$. Esta variedad tiene un grano de forma dentado, semi-cristalino y de color blanco.

Ambas variedades de maíz desarrolladas por dos enfoques diferentes de FP, resultaron tener características superiores a la población original del parental criollo Capulín, lo que sugiere que en principio, esta variedad poseía el potencial genético para responder a los procesos de selección (por hibridación y selección intrapoblacional) y permitir generar dos excelentes variedades (Hocdé 2006). Aunque en este documento no se ha presentado el proceso de FP para el mejoramiento de variedades criollas de maíz en comunidades del Lago Yojoa, cabe mencionar que en esta región se liberó la variedad de maíz "Carmen Palmichal", desarrollada a través de un proceso similar al descrito en la alternativa FP1 (Rosas y Mejía 2005).

Una variedad adicional de maíz desarrollada mediante la alternativa FP1, será liberada durante el 2006 en el municipio de Concepción del Sur, en la región del Lago Yojoa, con el nombre de "Olotillo Mejorado".

Las tres variedades de maíz desarrolladas mediante procesos de FP en Honduras, son en la actualidad las que se cultivan en mayor proporción en las comunidades participantes y vecinas; debido a que su proceso de adopción por los agricultores se inició durante las actividades de selección en las comunidades participantes. Las demandas de semilla de parte de usuarios de estas comunidades, han dado oportunidad para que algunos de los CIAL se vean involucrados en producción artesanal de semilla que es vendida en la misma región. La productividad del cultivo ha sido mejorada de manera significativa, lográndose mejores niveles de seguridad alimentaria y generación de ingresos a nivel local.

Las actividades de FP fueron precedidas por capacitaciones a técnicos y agricultores participantes, en Zamorano y en los CSP de cada localidad. Se desarrollaron los materiales didácticos necesarios para la capacitación y los instrumentos para las actividades de FP por los agricultores. Las primeras capacitaciones se basaron en los resultados del diagnóstico y en los fundamentos de mejoramiento y selección en maíz. Las capacitaciones siguientes se efectuaron de acuerdo a los avances en el proceso de FP, incluyendo la necesidad de introducir nuevos genes a las poblaciones criollas, la aplicación de criterios de selección, el mejoramiento y manejo de poblaciones, la conducción de ensayos para estimar los avances por ganancia de selección, la validación y la liberación de variedades mejoradas, el incremento de semilla y el mantenimiento genético de las variedades, y la producción comercial de semilla. 
Durante el proceso de FP se llevaron a cabo, con técnicos y agricultores, talleres de evaluación de los avances en la aplicación de las metodologías participativas y planificación de actividades. Personal de El Zamorano realizó visitas frecuentes a los CSP y fincas de los agricultores involucrados para observar la aplicación y los avances de las metodologías.

Debido a que las actividades propuestas en este proyecto estuvieron integradas a las de evaluación participativa con agricultores miembros de los CIAL asistidos por los proyectos participantes, cuando fue factible se condujeron días de campo para que los agricultores participantes divulgaran las actividades y avances en sus comunidades. Se hicieron los esfuerzos necesarios para que otras comunidades vecinas participaran en estas demostraciones, y se intentó medir la respuesta e inquietudes de los participantes. Para el caso de materiales en fases avanzadas de validación, de los que se dispuso de pequeñas cantidades de semilla, se promovió su diseminación hacia otras comunidades (mediante venta o trueque de semilla).

Se desarrollaron materiales divulgativos para las actividades de FP, y la capacitación y asistencia técnica necesarias. A los técnicos se les proporcionaron folletos y literatura sobre los principios y métodos de genética, además del mejoramiento de maíz, criterios para la evaluación y selección de poblaciones segregantes y variedades mejoradas, manejo de viveros, ensayos, la producción y distribución local de semilla mejorada. El material divulgativo para los agricultores incluyó aspectos similares pero con un lenguaje y contenido más prácticos, a fin de facilitar su aprendizaje.

Se desarrollaron las capacidades de técnicos y agricultores para determinar las demandas específicas de germoplasma mejorado según la problemática local, y de participar directamente en su desarrollo y utilización.

El Zamorano y las instituciones facilitadoras involucradas (FIPAH y el PRR) desarrollaron capacidades en la aplicación de metodologías de FP, y pudieron proveer capacitación, asistencia técnica o desarrollar proyectos para su aplicación en otras comunidades. Se pudo ampliar el acceso de los CIAL a germoplasma mejorado, y al desarrollo de variedades de maíz con adaptación local específica. La difusión de metodologías de FP durante el proyecto, y la respuesta de otras instituciones y comunidades a este enfoque, fue estimado a través de talleres y días de campo.

Durante la ejecución del Proyecto, se trató de medir el aprendizaje y desarrollo de habilidades y destrezas de los técnicos y agricultores participantes, a través de los resultados de selección y el seguimiento a las actividades de capacitación, enfatizando el registro de los avances en el desarrollo de la capacidad para aplicar principios y métodos de selección.

\section{LITERATURA CITADA}

ASHBY, J. A.; BRAUN, A.; GRACIA, T.; GUERRERO, M. P.; QUIROZ, C. A.; ROA, J. I. 2000. Investing in Farmers Researchers: Experience with Local Agricultural Research Committees in Latin America. Centro Internacional de Agricultura Tropical (CIAT), Cali, Colombia. 199 p.

COTTY, D.; GARCÍA, M.; ESTRADA, I.; ANCHUNDIA, E. 2001. Indicadores básicos sobre el desempeño agropecuario 1971-2000. Proyecto de Información Agrícola y Análisis de Políticas, Zamorano/USAID. Zamorano, Honduras. 110 p.

EYZAGUIRRE, P.; IWANAGA, M. 1996. Participatory plant breeding. Proc. Workshop on Participatory Plant Breeding. 26-29 July, Wageningen, The Netherlands. IPGRI, Rome, Italy, 164 p.

GARRIDO, J. 2004. Análisis comparativo de tres metodologías como alternativas de desarrollo en la Región del Yeguare. Ed. Guaymuras, Tegucigalpa, Honduras. 65 p.

GALLARDO, O. O.; JIMÉNEZ, J.; HERRERA, S. 2005a. Maíz Santa Cruz: Variedad de maíz blanco desarrollado para condiciones de altura. Boletín Técnico, Imprenta Litocom, Tegucigalpa, Honduras.

GALLARDO, O. O.; JIMÉNEZ, J. HERRERA, S. 2005 b. Capulín Mejorado: Variedad de maíz blanco desarrollado para condiciones de altura. Boletín Técnico, Imprenta Litocom, Tegucigalpa, Honduras.

GÓMEZ, F.; SMITH, M. E. 1996. Conservation and enhancement of maize with small farmers in 
Honduras. Cornell International Institute for Food, Agriculture and Development (CIIFAD), Project report, 15 p. (mimeografiado).

GÓMEZ, F.; BUESO, F. J.; RECONCO, R; HUGHES, P.; BENTLEY, J.; SMITH, M. 1995. Manual de mejoramiento y conservación del maíz criollo con pequeños agricultores. Escuela Agrícola Panamericana, Zamorano, Honduras. 37 p.

HUMPHRIES, S.; GONZALES, J.; JIMÉNEZ, J.; SIERRA, F. 2002. Lecciones de un programa de investigación participativa con agricultores de laderas. Impreso en Honduras. 95 p.

HOCDÉ, H. 2006. Fitomejoramiento participativo de cultivos alimenticios en Centro América: Panorama, resultados y retos. Un punto de vista externo. Agron. Mesoam. 17(3): 289-305.

PALIWAL, R. L.; GRANADOS, G.; HONOR, R. L.; VIOLIC, A. 2000. Tropical Maize: Improvement and Production. FAO, Rome, 363 p.

ROSAS, J.C.; MEJÍA, P. Z. 2005. Carmen Palmichal: Variedad de maíz desarrollada por los agricultores de El Palmichal, municipio de Taulabé, utilizando métodos participativos. Boletín Técnico, Imprenta Litocom, Tegucigalpa, Honduras.

ROSAS, J. C.; GALLARDO, O.; JIMÉNEZ, J. 2003. Mejoramiento genético del frijol común mediante enfoques participativos en Honduras. Agron. Mesoam. 14(1):1-9.

ROSAS, J.C. 2001a. Aplicación de metodologías participativas para el mejoramiento genético del frijol en Honduras. Agron. Mesoam. 12(2): 219-228.

ROSAS, J.C. 2001b. Enfoques participativos para el mejoramiento genético del frijol común y el maíz en Centro América. p. 8-16. In: D. L. Danial. ed. Memoria de la Conferencia Internacional sobre Futuras Estrategias para Implementar Mejoramiento Participativo en los Cultivos de las Zonas Altas en la Región Andina. Quito, Ecuador, 23-27 Septiembre 2001. Produgrafi Center, Quito, Ecuador. 197 p.

WELTZIEN, E.; SMITH, M. E.; MEITZER, L.S.; SPERLING, L. 2003. Technical and institutional issues in participatory plant breeding from the perspective of formal plant breeding. CGIAR Systemwide Program on Participatory Research and Gender Analysis for Technology Development and Institutional Development. CIAT, Cali, Colombia. 208 p. 